\title{
Percutaneous Salvage of a Thrombosed Immature Arteriovenous Fistula using a Long Segment Stent Graft across the Juxta-Anastomotic and Outflow Vein
}

\begin{abstract}
The role for stent grafting in the juxta-anastomotic segment for nonmaturing arteriovenous (AV) fistulas is not well understood. We report a case in which a long segment stent-graft of nearly the entire venous limb of a brachiocephalic AV fistula was stented to salvage an access that would likely otherwise have been abandoned. The patient went on to mature his fistula 3 months later and access it for hemodialysis through percutaneous puncture of the stent graft.
\end{abstract}

Keywords: Arteriovenous fistula, hemodialysis, interventional radiology, salvage therapy, stent

\section{Introduction}

Although stent placement to maintain patency of failing arteriovenous (AV) fistulas is well described, it is seldom reported for salvage of immature AV fistulas in the juxta-anastomotic segment. We report a technique for salvage of a clotted immature brachiocephalic fistula treated by placement of a long-segment stent graft across the entire juxta-anastomotic and outflow vein. Case reports are IRB exempt at our institution.

\section{Case Report}

A 64-year-old male with a medical history of end-stage renal disease status postfailed renal transplant and left upper extremity brachiocephalic AV fistula creation 1 month prior presented to interventional radiology with a nonmaturing and clotted fistula.

After patency of the left brachial artery was confirmed on ultrasound, the artery was accessed in retrograde fashion with a 3 French sheath. Angiography demonstrated a patent brachial artery with abrupt occlusion of the juxta-anastomotic vein $7 \mathrm{~mm}$ from the anastomosis [Figure 1]. The fistula was subsequently accessed at the level of the stump using a micropuncture set (Cook; Bloomington, IN). The occluded fistula was crossed with

This is an open access journal, and articles are distributed under the terms of the Creative Commons AttributionNonCommercial-ShareAlike 4.0 License, which allows others to remix, tweak, and build upon the work non-commercially, as long as appropriate credit is given and the new creations are licensed under the identical terms.

For reprints contact: reprints@medknow.com a Nitrex wire (Medtronic; Dublin, Ireland) and exchanged for a V18 wire (Boston Scientific; Marlborough, MA). A 5 French sheath was placed over the wire. A $4 \mathrm{~mm} \times 22 \mathrm{~cm}$ Coyote $^{\circledR} \quad$ (Boston Scientific; Marlborough, MA) balloon was used to angioplasty the juxta-anastomotic and outflow cephalic vein [Figure 2]. Postangioplasty imaging demonstrated no improvement of flow into the AV fistula. Angioplasty of the fistula was repeated with a $5 \mathrm{~mm} \times 10 \mathrm{~cm}$ Sterling ${ }^{\circledR}$ (Boston Scientific; Marlborough, MA) balloon. Postangioplasty angiogram demonstrated mildly improved flow, however persistent severe long segment stenosis of the juxta-anastomotic and outflow vein remained [Figure 3]. Over the wire, a $6 \mathrm{~mm} \times 25 \mathrm{~cm}$ Viabahn $^{\circledR}$ (W. L. Gore; Newark, DE) covered stent was deployed across this segment. The stent was then dilated with the $5 \mathrm{~mm}$ balloon. Completion angiogram demonstrated a patent arterial anastomosis and restored flow to the fistula extending to the central veins [Figure 4].

On discharge, the patient was prescribed $75 \mathrm{mg}$ Clopidogrel daily for 6 weeks to allow for epithelization of the stent graft. She returned at 3 months for follow-up, where a $\mathrm{CO}_{2}$ fistulogram was performed and confirmed fistula patency [Figure 5]. She subsequently underwent successful initiation of hemodialysis with cannulation of the stent graft for hemodialysis (HD) access.

\footnotetext{
How to cite this article: Ahmed $O$, Tran $P$, Hedroug Y, Turba UC. Percutaneous salvage of a thrombosed immature arteriovenous fistula using a long segment stent graft across the juxta-anastomotic and outflow vein. Arab J Intervent Radiol 2018;2:87-9.
}

\section{Osman Ahmed, Patrick Tran, Youssef Hedroug, Ulku Cenk Turba}

Department of Radiology, Rush University Medical Center, Section of Interventional Radiology, Chicago, IL, USA

Address for correspondence: Dr. Osman Ahmed,

Rush University Medical Center, 1725 W. Harrison Street, Suite 450, Chicago, IL 60612, USA.

E-mail: osman1423@gmail.com

Access this article online

Website: www.arabjir.com

DOI: 10.4103/AJIR.AJIR_14_18

Quick Response Code:

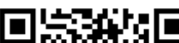
Fingtiry Pritritis:

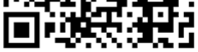




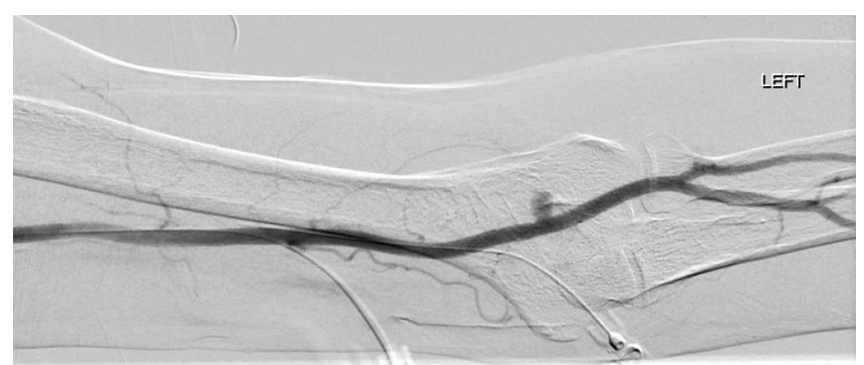

Figure 1: Left brachial arteriogram demonstrating abrupt occlusion of the arteriovenous fistula with a stump $7 \mathrm{~mm}$ from the arteriovenous anastomosis

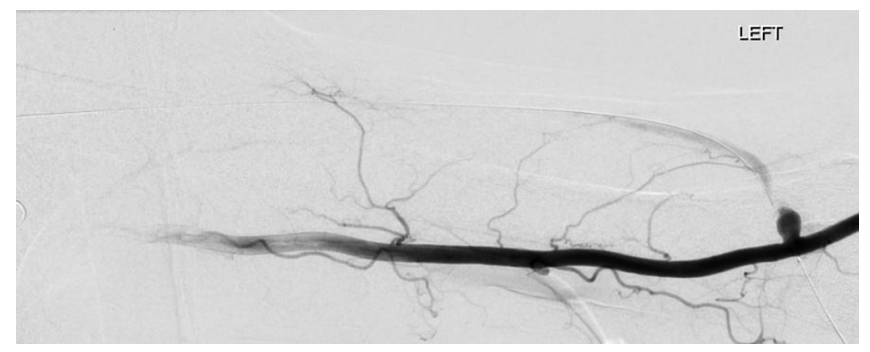

Figure 3: Postangioplasty fistulagram with minimal flow through the fistula. Severe long segment stenosis of the venous limb was also noted

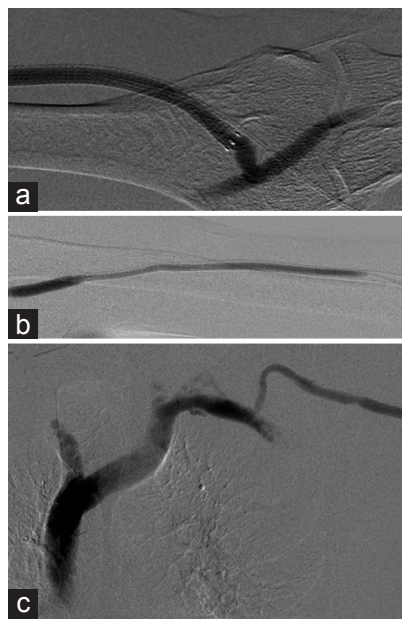

Figure 5: Three-month follow-up $\mathrm{CO}_{2}$ fistulagram demonstrates continued patency of the entire arteriovenous fistula from the anastomosis (a), outflow (b), and central veins (c). The fistula was subsequently accessed through the stent graft without complication

\section{Discussion}

Several studies currently describe percutaneous techniques for the salvage of immature AV fistulas using primarily balloon angioplasty or through embolization of collateral vessels. $^{[1]}$

Recently, juxta-anastomotic stenting (JXAS) has been described as an aggressive technique for salvage of immature fistulas. In a study of 68 patients between 2008 and 2012, the JXAS technique was successful in treating 33 immature fistulas and 35 "problem fistulas." This technique involved stenting stenotic areas at the anastomosis, $\pm 2 \mathrm{~cm}$ of the radial artery, and $\pm 5 \mathrm{~cm}$ of the

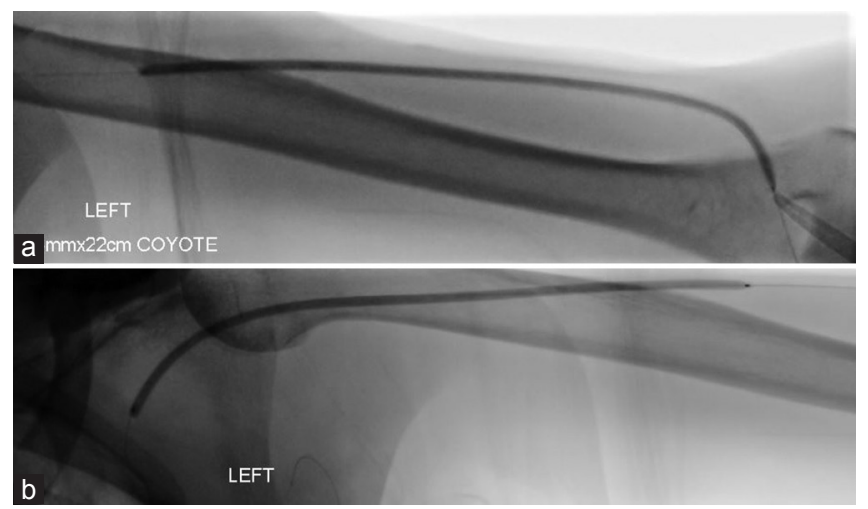

Figure 2: Spot radiographs demonstrating angioplasty of the juxta-anastomotic (a) and outflow (b) veins of the arteriovenous fistula

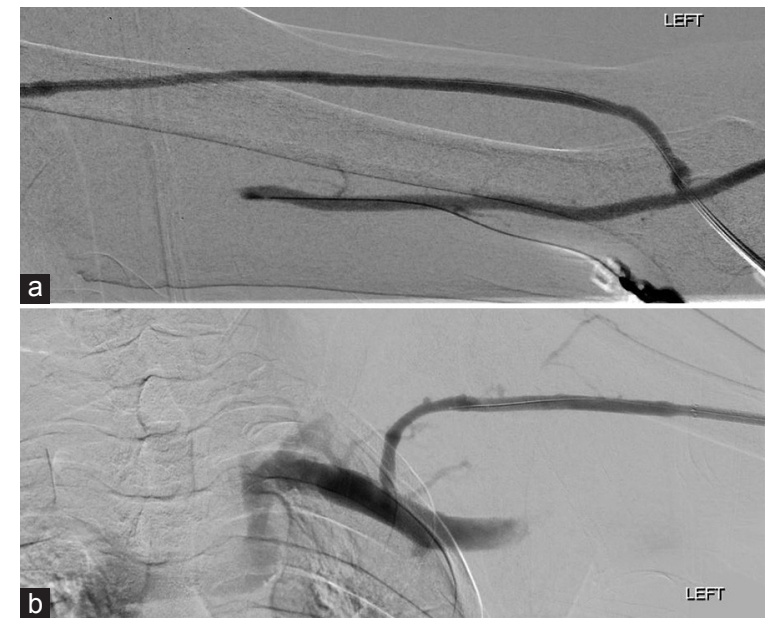

Figure 4: Poststenting fistulagram ( $a$ and $b$ ) now demonstrating restored patency to the arteriovenous fistula without residual thrombus or stenosis

swing vein. Of the immature fistulas treated, $75 \%$ matured at 6 months and $88 \%$ matured at 12 months. ${ }^{[2]}$ In the study, however, the length of segment stented and whether or not the cannulation site for access was covered were not mentioned.

In the present case, nearly the entire venous limb of the fistula was stented as a salvage maneuver for maturation, including the site for cannulation. Although avoiding stenting of the access site is typically desirable to prevent graft infection; in this circumstance, it was considered a last resort option as an alternative to abandoning the access. The feasibility of this technique was verified on follow-up fistulogram and successful cannulation of the fistula through the stent 3 months' postintervention.

Cannulation of a stent graft for hemodialysis access has been previously reported. In one study, two covered stents were used in the case of dilation-induced rupture not controlled by balloon tamponade. Stents were placed at the cannulation site and were then routinely cannulated for 
10 and 24 months, respectively. ${ }^{[3]}$ The current case differs in that stent placement was an intended maneuver to achieve maturation of a fistula and initiate hemodialysis.

\section{Conclusion}

Long segment stent-graft placement across the juxta-anastomotic and outflow vein of an immature AV fistula is a feasible alternative to abandonment of the access. The long-term viability of this technique at present requires further investigation.

\section{Declaration of patient consent}

The authors certify that they have obtained all appropriate patient consent forms. In the form the patient(s) has/have given his/her/their consent for his/her/their images and other clinical information to be reported in the journal. The patients understand that their names and initials will not be published and due efforts will be made to conceal their identity, but anonymity cannot be guaranteed.
Financial support and sponsorship

Nil.

Conflicts of interest

Osman Ahmed: Speaker, Spectranetics; Advisory Board Member, Bayer.

\section{References}

1. Zangan SM, Falk A. Optimizing arteriovenous fistula maturation. Semin Intervent Radiol 2009;26:144-50.

2. Swinnen J, Lean Tan K, Allen R, Burgess D, Mohan IV. Juxta-anastomotic stenting with aggressive angioplasty will salvage the native radiocephalic fistula for dialysis. J Vasc Surg 2015;61:436-42.

3. Turmel-Rodrigues L, Mouton A, Birmelé B, Billaux L, Ammar N, Grézard O, et al. Salvage of immature forearm fistulas for haemodialysis by interventional radiology. Nephrol Dial Transplant 2001;16:2365-71. 